\title{
The Effects of Wages on Aggregate Employment: A Brief Summary of Empirical Studies*
}

\author{
Elizabeth Webster \\ Melbourne Institute of Applied Economic and Social Research \\ The University of Melbourne \\ Melbourne Institute Working Paper No. 14/00 \\ ISSN 1328-4991 \\ ISBN 0734014945 \\ September 2000
}

* This paper was funded by the Business Council of Australia. Thanks are due to Joanne

Loundes and John Creedy for comments. Views expressed represent those of the author and all errors remain the responsibility of the author.

Melbourne Institute of Applied Economic and Social Research

The University of Melbourne

Victoria 3010 Australia

Telephone (03) 83445330

Fax (03) 83445630

Email melb.inst@iaesr.unimelb.edu.au

WWW Address http://www.melbourne institute.com 


\begin{abstract}
This paper provides non-technical summaries of theories which posit a relationship between aggregate employment and real wages and presents results from Australian and selected overseas empirical studies. Neoclasssical supply side theories assume that real wages, for given endowments of physical capital, primarily influence the cost of employing labour, and have an inverse relationship to aggregate employment. Keynesian demand side theories maintain that real wages affect both demand for labour as well as the relative costs of employing different techniques of production. Most estimations of the wage elasticity of demand for labour assume that real output is fixed and are thus not proper elasticities of demand. Recent Australian estimates range from -0.15 to -1.0 but the equations are not long run estimates as they include either output or the capital stock as an explanatory variable.
\end{abstract}




\section{Introduction}

The aim of this paper is to provide non-technical summaries of dominant theories which conjecture a relationship between aggregate employment and real wages and present results from Australian and selected overseas empirical studies. Macroeconomic policy makers and advisors cannot avoid holding a view about the size and scope of this relationship. This paper aims to highlight the main assumptions and ambiguities surrounding these issues.

The perception that at the aggregate level, real wage rates affect demand for labour is a long-standing and recurring theme in the economics literature. As the major costs of hiring labour, average wage rates relative to output prices have been considered one of the main arguments of the labour demand function. The generality of this view was challenged in 1936 by Keynes who argued that the dominant determinant of aggregate what was the level of effective demand. He drew attention to the possibility that changes to real wage rates were the outcome of the level of aggregate money demand and output. Keynes was also of the view that in cases where wage or price changes arise from factors other than the level of economic activity, the causal nexus is complex and ambiguous because wages affect both sides of the market, that is the costs of employment as well as aggregate

demand ${ }^{1}$ Subsequent to the acceptance of Keynes's analysis, models of the aggregate relationship between wages and employment have given at least token regard to aggregate demand considerations.

There are two schools of thought regarding the ability of empirical studies to reveal the size and sign of aggregate elasticities of labour demand. The first holds that carefully modelled, the size and sign of the elasticity between average wage rates and aggregate employment should be capable of empirical determination. The second view argues that the behavioural equations used for the supply side models produce estimating equations that 
are similar to accounting identities. Accordingly it is not possible to be sure that the estimated coefficients reflect behavioural elasticities or accounting parameters.

The first section in this paper describes a basic pre-Keynesian supply side model of aggregate employment, the second section describes models which include an aggregate demand function and the third section presents the results of selected empirical studies. While most of the papers assume that there exists an aggregate production function, this paper also reviews the accounting model of wages and employment.

\section{Models which do not include a demand function}

The archetypal aggregate supply side model assumes that the whole economy can be

represented as a single profit maximising firm. ${ }^{2}$ The employment decision is for each time period $t$ to minimise

$$
C=Y(w L+r K)
$$

subject to the production function

$$
Y=f_{1}(L, K) \text {. }
$$

Where $\quad C=$ total cost of production

$$
\begin{aligned}
& Y=\text { total real output } \\
& L=\text { labour inputs } \\
& K=\text { capital inputs } \\
& w=\text { real wages } \\
& r=\text { real cost of capital }=\text { the interest rate gross of depreciation (or capital user }
\end{aligned}
$$

cost).

$f_{1}$ is the functional form of the production function.

Stylised functional forms such as the Cobb-Douglas or Constant Elasticity of Substitution (CES) functions are usually chosen to represent $f$. Early versions of this model assumed that 
flexible relative input prices and variable output would ensure full employment for a given endowments of $L$ and $K$. However, these assumptions are of limited practical use as explanatory vehicles for explaining unemployment. Contemporary economists who use these models generally impose the restriction that relative factor prices, $(w / r)$, not $L$ are exogenously determined and thus unemployment is possible at above market clearing wage rates.

Solving for $L$ gives the labour demand function (time subscripts not shown)

$$
L^{*}=f_{2}\left(\frac{r}{w}, K\right)
$$

Taking logs and differentiating with respect to time gives an estimating equation

$$
\dot{l}=a_{0}+a_{1} \dot{w}+a_{2} \dot{r}+a_{3} \dot{k}
$$

Figure 1. Employment in a supply side model

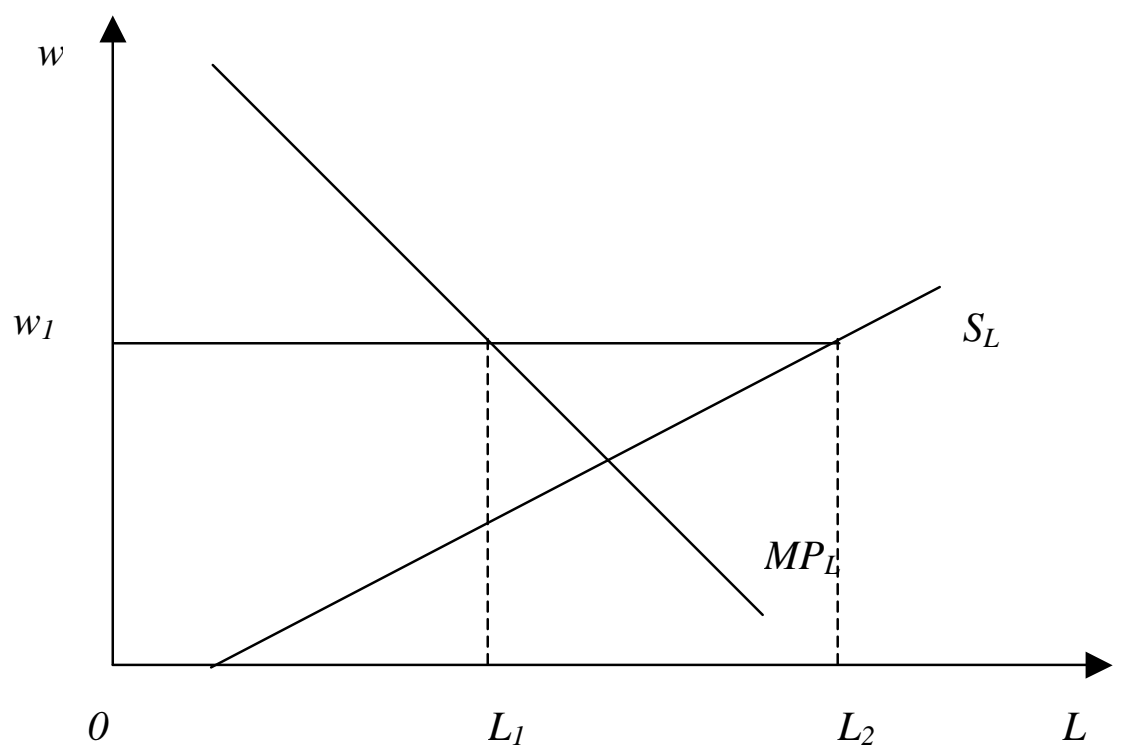

Where $\dot{w}, \dot{l}, \dot{r}$ and $\dot{k}$ are the continuous growth rates and the $a$ 's are coefficients (elasticities). In this model, the demand for labour depends on the relative price of labour and capital and the exogenously given capital stock. In Figure 1, the technologically determined Marginal Product of labour function, $M P_{L}$, is the demand for labour curve 
(prices are assumed to normalise at 1). At the given real wage $w_{1}$ employment is $O L_{1}$ and unemployment is $L_{1} L_{2}$. Only a fall in the real wage or rise in the stock of capital can increase employment.

Most empirical work using this type of model does not include the capital stock $K$ in the estimating equation, but uses instead the endogenous output variable $Y$ on the right hand side. Apart from the inappropriateness of this practise, it implies that the measured coefficients on the wages variable will be partial elasticities not total elasticities.

Neoclassical theory predicts that if $Y$ is held constant then a rise in $w / r$ will induce investments in labour savings technologies and comparatively more production in capital intensive products, thereby reducing employment in favour of capital. In this case a positive relationship should hold between relative factor prices and investment spending (holding output constant). Furthermore, a change in relative factor prices should also induce an observable shift in final demand from labour intensive to capital intensive industries.

It is also possible that a less direct relationship between wages and employment may exist than that outlined above. A Keynesian version of the aggregate labour market argues that a rise in wages lowers investment spending by increasing businesses projected investment costs. This lowers employment, capacity utilisation and output in the investment goods sector (in the first instance) and also possibly lower employment, capacity utilisation and output in the consumption goods sector. If the fall in employment is greater than the output fall, the output constant labour demand elasticity is negative.

However, estimation of equation (3) does not provide rigorous evidence of the existence of an underlying production function (of the form modelled) and subsequently of the operational significance of the estimated elasticities. It is also possible to derive a negative relationship between employment and wages from a simple national accounting 
identity. Following Shaikh (1974) and McCombie and Dixon (1991), the national income identity

$$
Y \equiv w L+r K
$$

can be transformed to produce the same or similar estimating equation as the cost minimising production function approach (assuming $Y, w, L, r$, and $K$ are functions of time). Differentiating (5) with respect to time $t$ and dividing both sides by $Y$ gives

$$
\begin{aligned}
& \frac{\partial Y}{\partial t} \frac{1}{Y} \equiv \frac{\partial w}{\partial t} \frac{L}{Y}+\frac{\partial L}{\partial t} \frac{w}{Y}+\frac{\partial r}{\partial t} \frac{K}{Y}+\frac{\partial K}{\partial t} \frac{r}{Y} \\
& \frac{\partial Y}{\partial t} \frac{1}{Y} \equiv \frac{\partial w}{\partial t} \frac{1}{w} \frac{w L}{Y}+\frac{\partial L}{\partial t} \frac{1}{L} \frac{L w}{Y}+\frac{\partial r}{\partial t} \frac{1}{r} \frac{r K}{Y}+\frac{\partial K}{\partial t} \frac{1}{K} \frac{K r}{Y}
\end{aligned}
$$

or

$$
\dot{y} \equiv b \dot{w}+b \dot{l}+(1-b) \dot{r}+(1-b) \dot{k}
$$

Where $\dot{y}, \dot{w}, \dot{l}, \dot{r}$ and $\dot{k}$ are continuous growth rates and $b$ is labour's share of national income.

Equation (8) can be expressed as

$$
i \equiv \frac{1}{b} \dot{y}-\dot{w}+\left(\frac{1-b}{b}\right) \dot{r}+\left(\frac{1-b}{b}\right) \dot{k}
$$

which is similar to equation (4).

An estimated equation that specifies

$$
i=f(\dot{y}, \dot{w})
$$

is similar to (9) if the two last terms are relatively constant. On the other hand, (10) could well be a mis-specified version of (9) with omitted variable bias. substituted for $\dot{y}$ in (10).

To summarise, the neoclassical supply side production function approach implies that (the growth in) labour demand is a function of (the growth of) relative factor prices and the 
(growth of the) stock of capital. This model specification is however the same as a model based solely on a national income identity. In both the behavioural (production function) and identity estimating equations, there is an a priori expectation that the sign of the coefficient on wages will be negative. It is not possible to know from the data which theoretical model is being represented by a general equation that has the rate of growth of employment on the left hand side and wages and output and/or the interest rate and capital stock on the right hand side. The choice will be based on a priori theoretical considerations.

\section{Models which include a demand function}

More common models of the aggregate employment relationship include an aggregate demand function. A minimum of two behavioural equations, an identity and a short period equilibrium condition (for each time period) are required. The general format is:

\section{$\underline{\text { Behavioural equations }}$}

An aggregate demand function

$$
Y^{d}=f_{3}\left(Y_{0}, w, r K, L\right)
$$

An aggregate production function

$$
Y^{s}=f_{1}(L, K)
$$

Where $Y_{0}=$ exogenous sources of demand (net trade surplus, government deficit etc).

An identity:

An aggregate income or cost function $\quad Y^{i} \equiv w L+r K$

A short period equilibrium condition:

All production is sold

$$
Y^{i}=Y^{d}=Y^{s}=Y
$$

The system can be solved for $L$ to get:

$$
L^{*}=f_{4}\left(w, r, Y_{0}\right)
$$

Long run models assume that $L, K$, and $Y$ are endogenous and $w, r$, and $Y_{0}$ are exogenous. Short run models treat $K$ but not $r$ as exogenous. It does not matter for estimation whether 
(13) is treated as a cost function to be minimised or as an aggregate income identity. Most papers however, treat (13) as a cost function and essentially assume that the economy is one sized-up cost minimising (profit maximising) firm. $L^{*}$ may not be unique and the solution is complex and likely to yield multiple equilibria even if simple functional forms for the production function are assumed.

Depending on the specification of the demand function, these models may incorporate Keynes's argument that demand is sensitive to both the level of wages and employment in addition to the effect of wages on costs of production. Few authors however follow this approach (Freebairn 1979 is one example). Valentine 1980 modelled demand for labour as a function of wages, employment, prices, profits and capacity utilisation. All variables except capacity utilisation were determined within the model but capacity utilisation was assumed to be exogenous. Debelle and Vickery (1998) modelled aggregate demand solely as a function of exogenous interest rates. In other cases, (Valentine 1980, Pissarides 1991) real wages are assumed to be endogenous and either a Phillips Curve or over-award wage equation is included in the system of equations. ${ }^{6}$ However, additional exogenous variables (such as award wages) must be included to close the system and provide a determinant solution. No authors canvass the possibility that a change to the level of output causes the real wage to change. 


\section{Figure 2. Employment when there is an aggregate demand function}

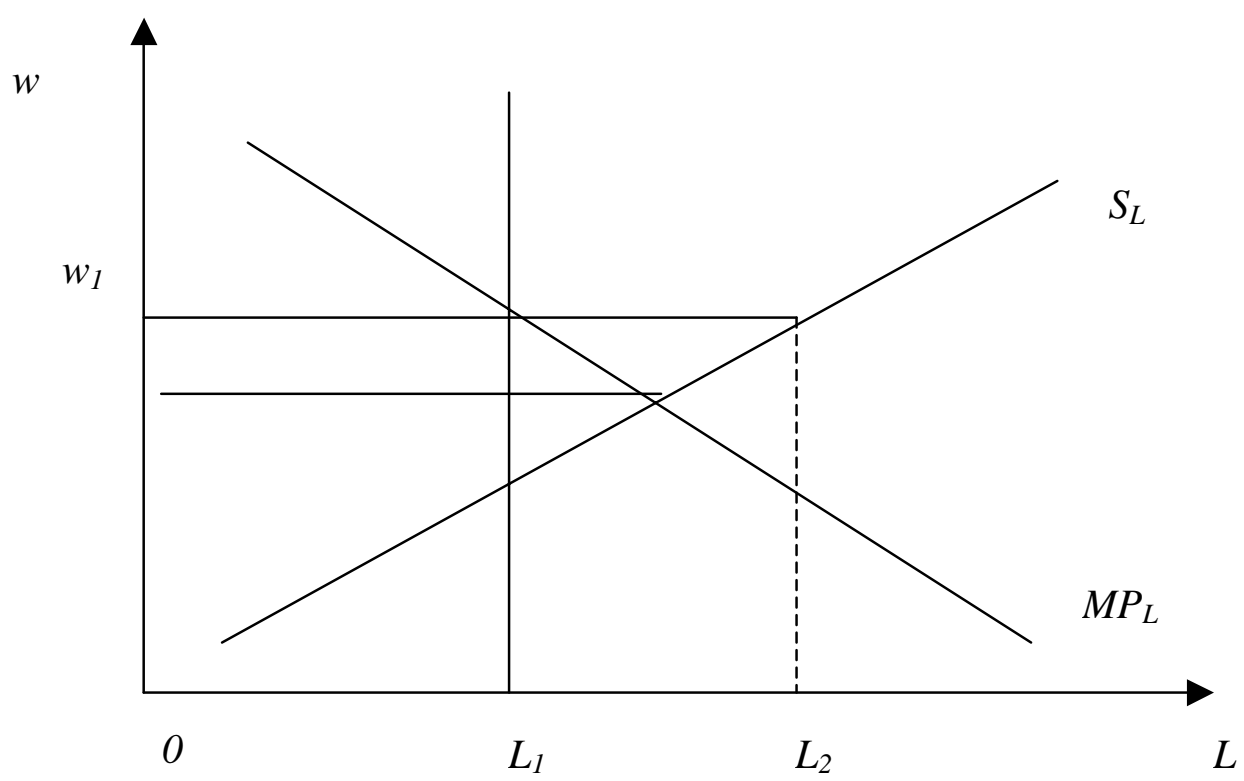

Figure 2 gives a simple representation of a model which includes an aggregate demand function $D_{L}$. This additional relationship (which may be positively or negatively sloped) maps the level of aggregate demand against real wages. $M P_{L}$ represents the maximum wage firms can pay and still make a normal profit at every level of aggregate employment. If a downward sloping curve is preferred, the $M P_{L}$ could be regarded as an ordered ranking of people in jobs from the high to low productivity rather than a strict Marshallian MP curve. In this model a fall in real wages from $w_{1}$ to $w_{2}$ will not automatically increase employment unless $D_{L}$ has a negative slope. The equilibrium level of employment is the minimum of the $M P_{L}$ and $D_{L}$ functions.

Adherents of the demand side approach sometimes regard the aggregate production function described above as theoretically misleading and reject its use. Capital $K$ is a produced commodity rather than a primary factor of production. Capital goods merely 
represent one stage in the production process which begins with primary inputs (labour and raw materials) and finishes with final outputs (consumption goods). Accordingly they argue that it is misleading to describe $K$ as an exogenous argument in the production function with a price of $r$.

While this logic is compelling, the conventional production function may nonetheless be a useful tool for some types of applied analyses. What modellers mean when they describe the production process as being more capital intensive (or requiring a higher $K / L$ ), is that the production process is more roundabout - that is, the series of dated labour inputs required for production are longer and/or involve more labour in earlier stages. In general, but not in all cases, more roundabout production processes cost more at higher discount rates relative to wages $(r / w)$ and it is possible to interpret, albeit in an imprecise way, the production function as if it mimics the long period production process.

However, if the model is only applied to short run responses of employment to a change in input prices then the assumptions of the model change. It takes time to affect all the stages of production. In the short period, capital costs (conventionally embodied as debt) cannot be reduced or increased due the nature of mortgages and the time lag involved in expanding the capital stock. Only employment is variable.

Unfortunately, most of the studies which have adopted a system of equations persist on including endogenous output $Y$ in the list of independent variables and not $Y_{0}$ exogenous sources of demand. This practise is careless and (as mentioned above) will only result in partial estimates of the full effect of real wages on the demand for labour. The accepted procedure for estimating equations is to derive the endogenous variable in terms of the exogenous variables. An explicit rationalisation should be given if this convention is not followed. 


\section{Multi-factor labour demand models}

One of the limitations of a 2-input model of the economy is that it assumes homogenous labour and, by design, forces labour and capital to be substitutes. Both these assumptions run counter to a body of literature in industrial and labour economics which highlights the importance of the heterogeneity of labour by skill and suggests dissimilar technological relationships between physical capital and different forms of human capital.

Models of demand for several types of labour may be similar to the above aggregate model except that the production function contains more than two factors.

A convenient cost function suggested by Hamermesh (1993 p39) is:

$$
C=Y \sum_{i} \sum_{j} a_{i j} w_{i}^{1 / 2} w_{j}^{1 / 2}
$$

or the translog function:

$\ln C=\ln Y+a_{0}+\sum_{i} a_{i} \ln w_{i}+1 / 2 \sum \sum b_{i j} \ln w_{i} \ln w_{j}$

with

$\sum_{i} a_{i}=1 ; \quad b_{i j}=b_{j i} ; \quad \sum_{i} b_{i j}=0, \forall j$

From (7) it can also be seen that the income identity for an economy with several factors:

$$
Y \equiv \sum_{i} d_{i} x_{i}
$$

where $\sum_{i} d_{i}=1$

can be transformed to

$$
\dot{y} \equiv \sum_{i} d_{i} \dot{x}_{i}+\sum_{i} \dot{d}_{i} x_{i}
$$

The applications of (19) to Australian data has been limited. 


\section{Summary of empirical studies}

Most of the supply side models are estimated with output as an explanatory variable. Hamermesh calls the resulting coefficients in the real wages variable, the constant output own wage elasticity of demand for labour'. Because of the difficulties incurred when measuring ex ante labour demand, aggregate employment is used as the dependent variable in most cases. This should not be an inherent problem for studies which assume the economy always operates on the Natural Rate of Unemployment (NRU) or those which are based on data since the mid-1970s. However it would be expected to bias the result for earlier studies. No studies reviewed below have considered the possibility that the empirical model may be merely capturing the accounting identities. However, the large changes in the functional distribution of income (the total wage bill relative to total profits) over the decades following the 1960s may violate the assumption that $b$ in (9) is constant.

Table 1 below presents a summary of selected Australian studies and overseas studies. Most studies which have an endogenous output in lieu of exogenous capital stock find significant coefficients in the range -0.15 to -0.8 . Some studies such as Russell and Tease (1991) and Lewis and Kirby (1988) implicitly allow the price of capital to vary (they do not control for $r$ ) and the estimates should therefore be regarded as elasticities of substitution or the slope of the isoquant, rather than labour demand elasticities. The former should theoretically be about twice the size of the latter although this is not always the case empirically. $\mathrm{Q}$ Debelle and Vickery $(1998,247)$ found that excluding $r$ from the estimated equation did not have an effect on the size of the other coefficients. This suggests that the estimates are not as close to the theoretical parameters as expected. In addition, many of these early studies include periods when there were general shortages of labour therefore 
the results should be treated with some caution as many observations are expected to be off the demand curve.

Studies which have not controlled for output generally find higher elasticities of demand. According to 11 studies surveyed by Hamermesh (1993) most coefficients were in the -0.15 to -1.5 range.

There are notionally four Australian studies which base their model on a system of equation including an aggregate demand function. Valentine (1980) has a 12 equation model with a quasi aggregate demand function but the estimating equations unfortunately include (endogenous) capacity utilisation as an explanatory variable..$^{[}$

The Debelle and Vickery (1998) model excludes discretionary government spending and the overseas sectors from the estimating model and assume an automatic central banking rule that maintains the rate of interest at a level to ensure full employment level of demand. By effectively neutering the aggregate demand function, the equilibrium demand for labour depends solely on the NRU or, in this case, the real wage. ${ }^{2}$ As such, the system of equations effectively operates as a supply side model even though a token aggregate demand function is included.

Even with a full system of equations in hand, Debelle and Vickery also include $Y$ as an argument of the estimating equation. While aware that $Y$ should not be treated as an exogenous variable, the authors chose to retain it in the equation and apply special treatment to the estimated coefficients instead. ${ }^{10}$ The latter involves estimating the magnitude of the effect of the real wage on the NRU and thus output. Debelle and Vickery do not estimate the size of this effect but utilise assumed values for a simulation of the whole model. The estimated constant output elasticity of demand is -0.40 . No estimate is given of the effect of a change in the real wage on the NRU. 
Bernie and Downes (1999) base their estimates of the constant output wage elasticity of demand on the Australian Treasury TRYM model. TRYM does not have a long run demand function $\frac{11}{1}$, and like Debelle and Vickery, this models effectively operates as a supply side model. Aggregate employment is determined by the exogenously given $w$ (in this version of the full model), and the $M P_{L}$ with the capital stock produces aggregate output. One advantage of the Bernie and Downes model is the inclusion of vacancies in the dependent variable and the restriction of the data to the private business sector where market incentives are considered strongest. The estimated constant output elasticity of demand is -0.84 . Bernie and Downes also re-estimate the Debelle and Vickery equation with private sector data and vacancies (added to employment) and get a constant output estimate of -1.04 .

Finally, Hamermesh's review of overseas models which includes several types of labour found that lesser educated or manual labour have higher own wage elasticities of demand and there is some but not clear evidence that they are more likely to be a substitute for physical capital than more educated or non-manual labour. The sole Australian study by Lewis (1985) found that the own wage elasticities of demand were inelastic for junior males, females and adult females. 
Table 1. Summary of estimates of wages elasticity of labour demand

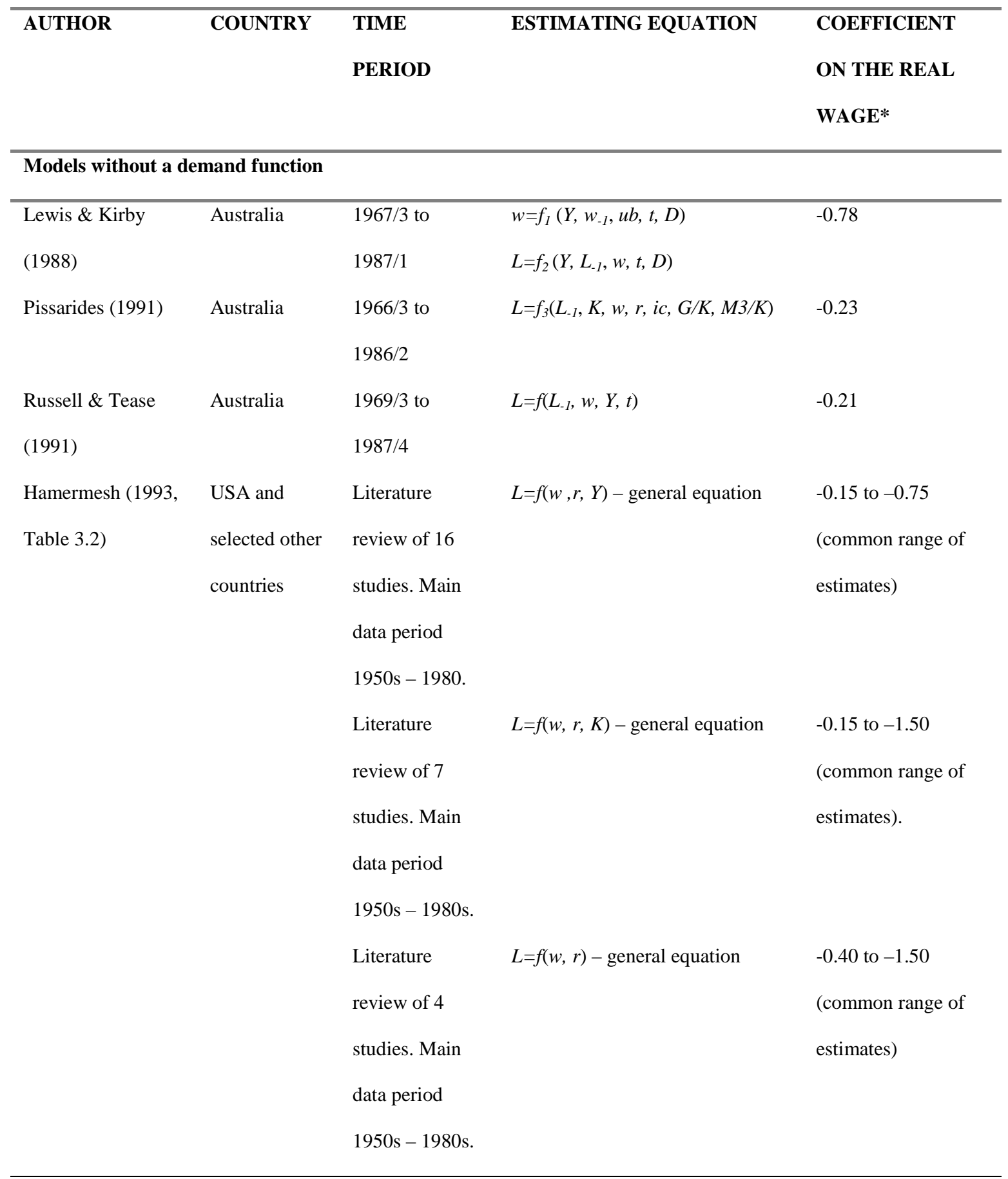




\begin{tabular}{|c|c|c|c|c|}
\hline \multicolumn{5}{|c|}{ Models which include a demand function } \\
\hline \multirow[t]{2}{*}{ Valentine (1980) } & Australia & $1959 / 4$ to & $L=f\left(L_{-l}, K U, w, t, D\right)$ & -0.03 \\
\hline & & $1977 / 2$ & $w=f\left(w_{-1}, a w, K U, t, D\right)$ & \\
\hline \multirow[t]{2}{*}{ Debelle \& Vickery } & Australia & $1978 / 1$ to & $L=f(Y, r / w, t)$ & -0.40 \\
\hline & & $1997 / 4$ & & \\
\hline \multirow[t]{5}{*}{ Bernie \& Downes } & Australia & $1971 / 2$ to & $L=f\left(Y_{-1}, h, w, t\right)$ & -0.84 \\
\hline & & $1998 / 3$ & & \\
\hline & Australia & $1969 / 1$ to & $L=f(Y, w, t)-$ reestimation of & -1.04 \\
\hline & & $1997 / 4$ & Debelle \& Vickery (1998) using & \\
\hline & & & private sector data and vacancies & \\
\hline
\end{tabular}

\begin{tabular}{|c|c|c|c|c|}
\hline \multicolumn{5}{|c|}{ Models including several types of labour } \\
\hline Hamermesh (1993, & USA and & Literature & $L=f\left(\ln w_{1} \ln w_{2}, \ln w_{3}, \ldots \ln r\right)-$ & Blue collar more \\
\hline \multirow[t]{9}{*}{ Table 3.7) } & selected other & review of 14 & translog cost functions & likely to be a \\
\hline & countries & studies. Labour & & substitute for capital \\
\hline & & divided as white & & than white collar. \\
\hline & & and blue collar. & & Blue collar has \\
\hline & & Main data & & higher own wage \\
\hline & & period 1950 s - & & elasticity. Some but \\
\hline & & 1980. & & not clear evidence of \\
\hline & & & & skill-capital \\
\hline & & & & complementarity. \\
\hline \multirow[t]{7}{*}{ Hamermesh (1993, } & USA and & Literature & $L_{i}=f\left(\ln w_{1} \ln w_{2}, \ln w_{3}, \ldots \ln w_{I}\right.$ & Less educated labour \\
\hline & selected other & review of 17 & $\ln r)-$ translog cost functions & more likely to be a \\
\hline & countries & studies. Labour & & substitute for capital \\
\hline & & divided by & & than more educated. \\
\hline & & education. Main & & Less educated labour \\
\hline & & data period & & has higher own wage \\
\hline & & $1960 s-1980$. & & elasticity. Strong \\
\hline
\end{tabular}


capital substitution.

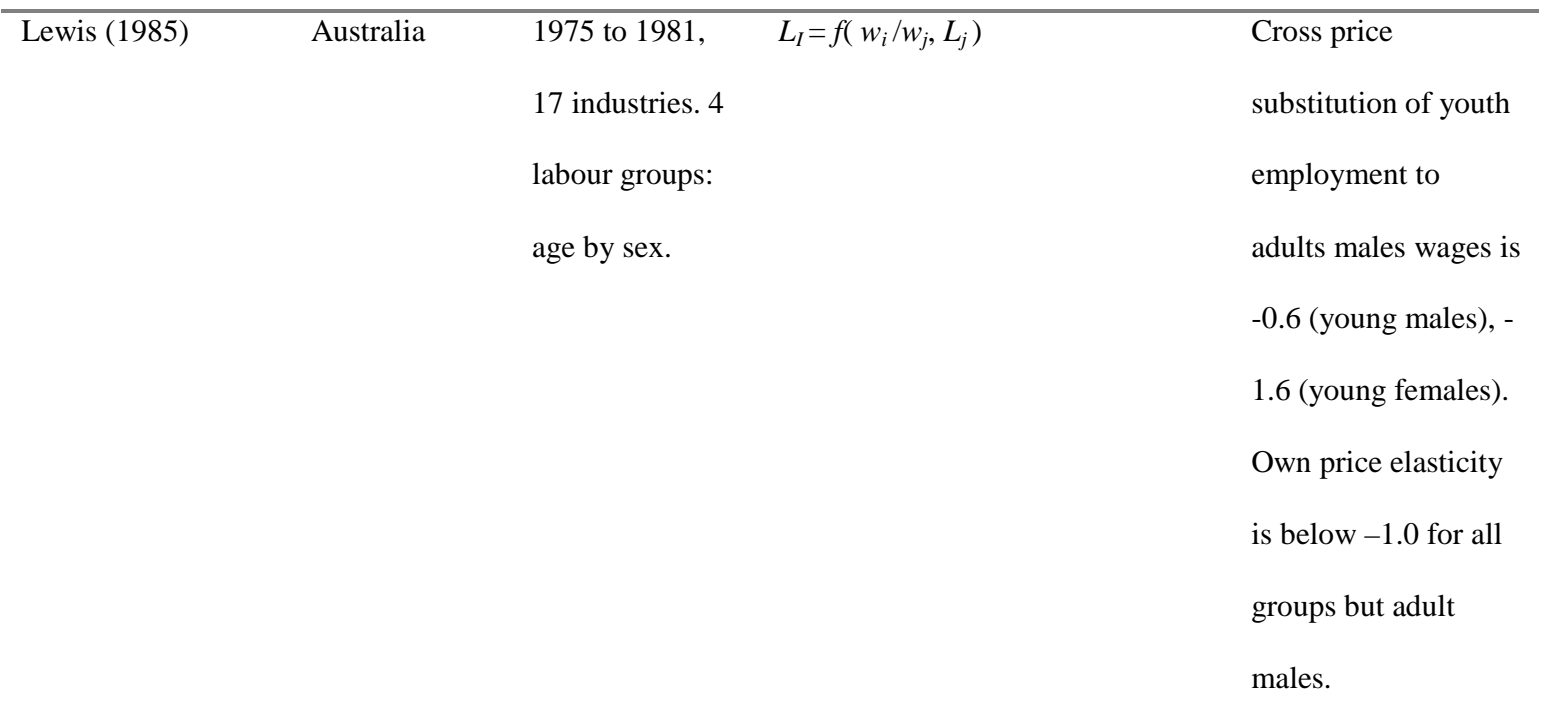

Notes: * If $Y$ is included in the equation the coefficient refers to the constant-output wage elasticity of demand. Unless otherwise specified the cited elasticity represents the long run estimate. In most cases this refers to about 4 quarters of adjustment and we would expect this to be considerably shorter that the time requires to work though all the stages of production (the full long period).

Additional variables: $\mathrm{ub}=$ unemployment benefits, $\mathrm{D}=$ dummies (usually for incomes policies) $\mathrm{t}=$ time trend (usually a proxy for technological change), ic = international competitiveness, $\mathrm{G}=$ government expenditure, $\mathrm{M} 3=\mathrm{M} 3$ money stock, $\mathrm{KU}=$ capital utilisation rates, aw = exogenously given award wages, $\mathrm{h}=$ hours of work.

\section{Conclusion}

Australian and overseas estimates of the constant output elasticity of demand for labour are in general inelastic being in the range -0.15 to -0.8 . The recent Australian estimate by Bernie and Downes using private sector data and including vacancies produced an estimate of about -1 . Estimates which do not hold output constant find on average higher aggregate elasticities. There are theoretical reasons for including an aggregate demand function but no recent Australian studies embody one. Furthermore, there is no theoretical reasons why the estimating function should include output as an explanatory variables. It is always endogenous as one of the main ways relative factor prices can affect employment is through 
its effect on the profit maximising level of production. Little discussion is given in the literature of this issue and its practise is questionable.

Multi-factor studies employ more divergent modelling methods and the resulting elasticities vary considerably from study to study. As a generalisation based predominantly on the summaries given by Hamermesh, the elasticity of demand are higher for less skilled and less educated labour than for more skilled and more educated labour. Furthermore, less skilled labour appears to be a gross substitute for physical capital and more skilled labour tends to be a complement for physical capital.

No Australian studies appear to have entertained the possibility that the coefficients are reflecting (partly mis-specified) coefficients from the income accounting identities rather than elasticities of demand. Without some discussion of this issue, the treatment of the important issue of the sensitivity of aggregate labour demand to change in relative factors prices is unsatisfactory.

\section{References}

Bernie, K. and Downes, P. (1999), 'The macroeconomics of unemployment in the Treasury Macroeconomic (TRYM) model', RBA Seminar Series, .

Debelle, G. and Vickery, J. (1998) The macroeconomics of Australian unemployment, In Unemployment and the Australian Labour Market Reserve Bank of Australia and Centre for Policy Research, ANU, Sydney.

Freebairn, J. W. (1979), 'Do wages matter?', Australian Economic Review, 3 Qtr, 25-35.

Hamermesh, D. S. (1993) Labor Demand, Princeton Academic Press, Princeton, NJ.

Lewis, P. E. T. and Kirby, M. G. (1988), 'A new approach to modelling the effects of incomes policies', Economics Letters, 28, 81-85. 
McCombie, J. S. L. and Dixon, R. (1991), 'Estimating technical change in aggregate production functions: a critique', International Review of Applied Economics, 5, 2426.

Pissarides, C. A. (1991), 'Real wages and unemployment in Australia', Economica, 58, 3555.

Shaikh, A. (1974), 'Laws of production and laws of algebra. The humbug production function', Review of Economics and Statistics, 56, 115-20.

Valentine, T. (1980), 'The effect of wage levels on prices, profits, employment and capacity utilisation in Australia: An econometric analysis', Australian Economic Review, 1'80, $13-22$.

1 Keynes (1973, [1936], Ch 19, Appendix 3).

2 More detail can be found in Hamermesh (1993).

3 Other factors such as technological change may be included as an additional argument in the $f_{1}$ function.

${ }^{4}$ If $L$ is exogenous the labour demand function should be represented as a maximum wage function, that is, $w / r$ as a function of $L$ and $K$.

5 Omitted variables can produce biased and inconsistent estimates and biased standard errors of the estimates. As such the usual confidence intervals and hypothesis testing procedures are likely to given misleading conclusions about the significance of the estimates.

6 There are a number of additional relationships which can be added on to this basic model such as taxation, dummies for specific government policies etc. Some models incorporate price illusion and define the model in nominal terms.

7 See Hamermesh $(1993,24)$.

${ }^{8}$ This makes it difficult to assess the full effects of real wages on aggregate employment as a major effect of changing real wages may be via its effect on the level of economic activity and capacity utilisation.

9 Debelle and Vickery $(1998,243)$.

${ }^{10}$ They opt in one case to instrument $Y$ and also to use a chain rule to convert partial elasticities into total elasticities. In the latter case they need to make and estimate the effect of a change in real wages on the NRU and thus on output.

${ }^{11}$ What they call the long run demand function is the maximum real wage payable to labour given the level of technology and institutional factors such as the tax wedge. 